\title{
Reliability and Concurrent Validity of Korean Version of the Trunk Control Measurement Scale (K-TCMS) for Children with Cerebral Palsy
}

\author{
Jooyeon $\mathrm{Ko}^{1}$, Jeewoon Jung ${ }^{2}$ \\ 'Department of Physical Therapy, Daegu Health College, Daegu; ${ }^{2}$ Department of Rehabilitation Therapy, Graduate School of Hallym University, \\ Chuncheon, Korea
}

Purpose: This study was conducted to develop a Korean version of the trunk control measurement scale (TCMS) and examine the reliability and concurrent validity of the K-TCMS in children with cerebral palsy.

Methods: Subjects for the study were 23 children with cerebral palsy (CP)(mean age: 84.70 months) recruited from one CP clinic. For the interrater and test-retest reliabilities, four raters $(A, B, C, D)$ measured the K-TCMS two times using video clips with an interval of two weeks. For the concurrent validity, the Korean version of the gross motor function measure (K-GMFM) was chosen. Inter-rater reliability and test-retest reliability of the three K-TCMS subscale (static sitting balance, dynamic sitting balance and dynamic reaching) scores and the total scores were investigated using the intra-correlation coefficient $\left(\mathrm{ICC}_{3,1}\right)$. Spearman's correlation coefficient $(r)$ was calculated to investigate the concurrent validity.

Results: The inter-rater reliability of the K-TCMS subscales and total scores were all high $\left(\mathrm{ICC}_{3,1}=0.968-0.992\right)$. For the test-retest reliability, $I C C_{3,1}=0.827-0.962$. The concurrent validity between the K-TCMS's total and three subscale scores and K-GMFM's total score were $r=0.600-0.667$.

Conclusion: The results suggest that the K-TCMS can be used in clinical and research settings as a standardized tool for CP children. The K-TCMS might be also useful for selecting treatment goals and planning interventions for children with cerebral palsy.

Keywords: Trunk control measurement scale (TCMS), Reliability, Validity

\section{서 론}

뇌성마비는 움직임과 자세의 장애뿐 아니라 일상생활기술, 의사소 통, 사회성, 이동성 영역에서 활동제한이 따르고 대개의 경우 감각, 인 식, 인지, 언어, 행동발달에도 손상이 따르는 아동기의 대표적인 기능 장애다. 자세조절의 장애는 기능 수준에 상관없이 뇌성마비에 따르 는 뚜렷한 특징이다. ${ }^{2-4}$ 다양한 환경에서 앉기, 걷기, 놀이터 및 학교활 동 등과 같은 기능적 활동과 참여를 위하여 몸의 해당 부분 또는 전 체 자세를 자유로이 조절해야 한다. ${ }^{5}$ 근육. 골격계통과 신경. 감각계 통의 복잡한 상호작용을 거쳐 장기적으로 발달하는 자세조절에서 몸통은 매우 중요한 역할을 한다. ${ }^{6}$ 몸통 근육은 척추와 몸통을 안정 화시키고 이를 바탕으로 머리와 팔.다리에서 자유롭고 선택적인 움 직임이 이뤄지고, 뻗기와 걷기에서는 몸통이 능동적으로 참여한다.7.8

Received Jan 16, 2017 Revised Feb 28, 2017

Accepted Feb 28, 2017

Corresponding author Jooyeon Ko

E-mail 7806218@hanmail.net
물리치료적인 관점에서, 뇌성마비아동의 몸통조절과 관련한 근거 중심물리치료를 수행하기 위해서는 표준화된 평가도구를 활용하여 몸통조절 손상수준의 확인, 목표설정, 중재계획 및 중재결과평가 등 이 이루어져야 한다.9,10

위와 같이 임상 및 연구상의 중요성에도 불구하고 뇌성마비아동의 몸통조절 장애를 평가할 수 있는 도구는 매우 제한적이다. Seated postural control measure (SPCM) ${ }^{11}$ 그리고 spinal alignment and range of motion measure $(\mathrm{SAROMM})^{12}$ 는 앉은 자세에서 정적인 자세정렬상태를 평 가한다. SPCM은 신뢰도가 낮고 SAROMM은 몸통의 자세적 특성에 관한 정보만 제공해 줄 뿐 정적 혹은 동적 조건에서 몸통조절에 대한 어떠한 정보도 구할 수 없다. 최근에 segmental assessment of trunk con$\operatorname{trol}(\mathrm{SATCo})$ 가 새롭게 개발되었지만 ${ }^{13}$ 이 평가도구는 지지하고 앉은 자 세, 머리를 움직일 때, 외부에서 자세동요가 있을 때 안정적으로 앉은 
자세를 유지하는 능력을 평가할 뿐이다. 소개한 3 가지 평가도구들은 기능적 활동을 수행하는 데 필요한 정적 그리고 동적 몸통조절력을 측정해주지 못한다. 최근, 뇌졸중 환자의 몸통조절력을 평가해주는 trunk impairment scale (TIS)을 바탕으로 뇌성마비아동의 몸통조절력 을 측정해주는 아동용몸통조절측정척도(trunk control measurement scale, TCMS)가 개발되었다. TCMS는 앉은 자세에서 정적 및 동적 몸통 조절력을 평가한다. ${ }^{14}$ 뇌성마비아동의 앉은 자세에서의 균형능력은 활 동과 참여를 향상시키기 위한 중재를 계획하는 데 있어 기본이 되므로 ${ }^{15}$ TCMS가 개발된 이후로 뇌성마비아동의 몸통조절력과 기능적 활동 간의 연관성을 알아보고 중재를 계획하는 데 널리 쓰이고 있다.16-18 최 근 보행이 가능한 뇌성마비아동을 대상으로 몸통조절력과 보행이상 의 연관성을 검사하는 연구에서 성공적인 보행중재에 몸통의 역할이 크게작용하는 대상자를 선별하는 데 TCMS를 사용하였다.15

국내의 실정도 다르지 않아 뇌성마비아동의 몸통조절 능력을 측 정할 수 있는 평가도구가 필요하다. 따라서 본 연구에서는 국내의 TCMS에 대한 높은 관심과 임상 및 연구목적에 적용할 수 있는 유용 한 자료를 제공하기 위하여 TCMS를 한국판으로 표준화하고자 하며 구체적인 목적은 다음과 같다.

첫째, 영어로 된 TCMS를 한국어번역, 영어번역, 한국어 재 번역 과 정을 거쳐 한글화된 TCMS 매뉴얼을 개발한다. 둘째, 한글화된 $\mathrm{TCMS}$ 의 검사자 간 그리고 검사-재검사 신뢰도를 확인한다. 셋째, 원 저자의 검증을 받은 최종 매뉴얼과 신뢰도를 바탕으로 완성된 한국 판아동용몸통조절측정척도(Korean version of trunk control measurement scale, K-TCMS)와 한국판대동작기능평가(Korean version of gross motor function measure, K-GMFM) 간의 공인타당도를 조사한다.

\section{연구 방법}

\section{1. 연구대상}

한글화된 TCMS의 신뢰도, 타당도, 민감도를 조사하기 위하여 병원 에서 외래치료를 받는 뇌성마비아동 23 명을 대상으로 하였다. 대상 자 선정조건은 뇌성마비로 진단받은 대동작기능분류체계(gross motor function classification system, GMFMC) 제 I-III 단계의 치료사의 지 시를 듣고 이해할 수 있는 아동을 대상으로 하였다. 실험참가 4 개월 전에 보톡스 시술을 받았거나 실험 참가 6 개월 전에 정형외과적 수 술을 받은 아동은 대상자에서 제외하였다. 연구대상자의 일반적 특 성은 Table 1에서 보는 바와 같다.

\section{2. 실험방법}

\section{1) 아동용몸통조절측정척도(TCMS)}

아동용몸통조절측정척도는 15 개 항목으로 구성되며 테이블에 걸쳐
Table 1. General characteristics of the sample $(N=23)$

\begin{tabular}{lc}
\hline Variable & \\
\hline Age (month) & $84.70(45.79)$ \\
Sex & $13(56.52)$ \\
Boy & $10(43.48)$ \\
Girl & \\
GMFCS levels & $11(47.83)$ \\
I & $5(21.74)$ \\
II & $7(30.43)$ \\
III & \\
CP types & $21(91.30)$ \\
Spastic & $2(8.70)$ \\
Dyskinetic & \\
\hline
\end{tabular}

Values are n (\%), GMFCS: gross motor function classification system.

앉아 기능적 활동을 수행하며 앉은 자세에서의 균형능력, 즉 몸통조 절능력을 평가한다. 정적 앉기 균형능력(static sitting balance), 동적 앉 기 균형능력(dynamic sitting balance) 그리고 동적 팔 뻗기 또는 균형 반응(dynamic reaching 또는 equilibrium reaction) 등 3 개의 하위척도 로 구성된다. 각 항목마다 공통적으로 시작자세(팔이나 발을 지지하 지 않고 치료용 테이블 가장자리에 걸쳐 앉기)를 준수해야 한다.

'정적 앉기 균형능력에서는 시작자세 10 초 유지하기, 양팔 눈 높이로 1 초 안에 들어올리고 시작자세로 돌아오기, 치료사가 한쪽 다리를 다 른 쪽 다리 위로 교차시켜주면 10 초간 자세 유지하기, 아동 스스로 다 리 교차하기, 시작자세에서 한쪽 다리를 $10 \mathrm{~cm}$ 벌리고 시작자세로 다시 돌아오기 등 5 개 항목을 평가한다. 1,2 번 항목은 양측을 같이 평가하고 3-5번은 왼쪽, 오른쪽을 각기 평가하며 각기 0-2점, 0-2점, 0-2점, 0-3점 그 리고 0-3점을 부여하여 총 0-20점의 점수범위를 갖는다. 동적 앉기 균형 능력에서는 시작자세에서 양팔을 가슴 앞으로 교차하여 전방으로 $45^{\circ}$ 기울이고 시작자세로 돌아오기, 후방으로 $45^{\circ}$ 기울이고 시작자세로 돌 아오기, 시작자세에서 대퇴골두 위치에 팔꿈치가 닿게 한 후 시작자세 로 돌아오기, 한쪽 골반 들어올리고 시작자세로 돌아오기, 양팔을 가슴 앞으로 교차하고 상부몸통 3 회 회전, 하부몸통 3 회 회전, 골반 전방으 로 3 회 움직인 후 후방으로 다시 3 회 움직여 시작자세로 돌아오기 등 크 게 7 개 항목이지만 항목마다 세부항목이 있어 총 16 개 항목을 평가한 다. 8,9 번은 왼쪽, 오른쪽을 각각 측정하고 나머지는 한꺼번에 검사한 다. 점수범위는 6, 7번은 0-1점, 0-2점, 0-3점 범위를 가지며 총점은 범위 는 0-28점이다. '동적 팔 뻗기 또는 균형반응에서는 시작자세에서 앞으 로 팔 뻗기, 옆으로 팔 뻗기, 신체중심선을 가로질러 팔 뻗기 등 3 개 항목 을 측정한다. 13 번은 양측을 동시에 그리고 14,15 번은 양쪽을 따로 측정 한다. 항목별 점수범위는 0-2점 총점범위는 0-10점이다. 왼쪽과 오른쪽 을 각각 측정하는 항목들을 포함해서 실제로는 총 35 개 항목을 평가하 며 총점의 점수범위는 0-58점이다. 본 연구에서 사용한 한국판아동용 
몸통조절측정척도는 Appendix 1에서 확인할 수 있다. TCMS는 ICF장 애모델에서 신체기능 및 구조와 활동영역을 평가한다. ${ }^{19}$ 또한 K-TCMS 는 준거참조(criterion-referenced) 평가도구로써 몸통조절의 손상 수준 확인, 치료목표 수립, 중재계획에 적용할 수 있다.20

\section{2) 한국판대동작기능분류체계(Korean version of gross motor}

\section{function classification system, K-GMFCS)}

1997년 Palisano 등21이 뇌성마비아동의 독립적 이동성을 객관적으로 분류할 목적으로 개발한 국제적 분류기준이다. 0-18세 아동을 대상 으로 0-2세, 2-4세, 4-6세, 6-12세 그리고 12-18세 등 6개 연령대로 나누 고 네발기기, 걷기 그리고 보조도구의 사용을 기준으로 다음과 같이 5 단계로 분류한다. 제 I 단계는 제한 없이 보행이 가능하고, 제 II 단계 는 제한적인 보행, 제 III 단계는 워커, 크러치, 수동휠체어 등 이동보행 보조도구를 이용하여 보행하고, 제 IV 단계는 제한적으로 자가보행 이 가능하고 전동휠체어를 사용하기도 하며, 마지막으로 제 V 단계 는 전적으로 타인에 의한 이동을 한다. 본 연구에서는 아동용몸통조 절측정척도의 시작자세(아동의 등, 팔 또는 발이 바닥에 닿지 않게 치 료용테이블 가장자리에 걸터앉는다)를 취하고 유지할 수 있는 GMFCS 제 I-III 단계의 아동을 대상으로 하였다. 한국판대동작기능분류 체계의 측정자간신뢰도는 ICC $=0.972-0.988$ 이다.22

\section{3) 한국판아동용몸통조절측정척도 개발과정}

한국판아동용몸통조절척도의 개발을 위하여 연구자는 원저자인 Heyrman으로부터 아동용몸통조절척도의 한글화에 대한 승인을 받 고 표준화에 대한 계획을 공유하였다. 외래어로 된 평가도구의 한국판 개발을 위한 기본 절차인 한글번역, 영문으로 재 번역, 원저자와 문화 적 및 언어적 차이에 따른 내용 수정, 그리고 다시 한글번역 과정을 거 쳐 한글화된 아동용몸통조절척도를 준비하였다. 이 과정에서 '동적 앉기 균형능력' 하위척도 6 번 항목 시작자세에서 양팔을 가슴 앞으로 교차하여 전방으로 $45^{\circ}$ 기울이고 시작자세로 돌아오기', 7 번 항목 '후방 으로 $45^{\circ}$ 기울이고 시작자세로 돌아오기에서 원저자는 영문 재번역본 에 대하여 "I use a large goniometer to define this angle. I use my hand as a target for the patient to move its trunk and to touch my hand. - also both forward and backward movement needs to be taken into account for scoring" 라는 코멘트를 달아 각도계로 $45^{\circ}$ 각도를 측정할 것을 권고하면서 검사자가 $45^{\circ}$ 위치에 손을 들고 아동이 몸통을 손 위치까지 기울이게 하는 방법도 제안하였다. 이 외에도 항목마다 원저자의 코멘트를 바탕 으로 영어로 된 아동용몸통조절척도를 한글매뉴얼로 개발하였다.

한국판아동용몸통조절척도의 개발을 위하여 위와 같이 완성된 한글판 아동용몸통조절척도를 사용하여 신뢰도와 공인타당도를 조사하였다.

\section{4) 신뢰도 및 공인타당도 조사}

한글화된 아동용몸통조절척도의 신뢰도와 공인타당도 조사에는 단일기관에 근무하는 뇌성마비아동 치료 및 평가 경험이 3년 이상 (학사 혹은 석사이상, 3년 2개월-7년 5개월)된 아동물리치료사6명(A, $\mathrm{B}, \mathrm{C}, \mathrm{D}, \mathrm{E}, \mathrm{G})$ 이 참여하였다. 치료사 $\mathrm{E}, \mathrm{G}$ 는 대상자를 2 주 간격으로 2 회에 걸쳐 아동용몸통조절척도를 사정하고 그 내용을 비디오레코딩 하였고, 나머지 A, B, C, D 4명은 준비된 비디오클립을 보면서 실제로 검사자 간 및 검사-재검사신뢰도 조사에 참여하였다. 실제 측정에 앞 서 본 연구자가 위의 6 명의 치료사에게 아동용몸통조절척도의 각 항목의 내용에 대한 이론 교육과 뇌성마비 아동 2 명을 비디오 촬영 하여 평가자 모두 $80 \%$ 이상 일치된 점수가 나올 때까지 실기훈련을 실시하였다. 치료사 A, B, C, D는 준비된 비디오 클립을 보면서 한글 화된 TCMS의 항목별, 3 개의 하위척도, 그리고 총점 등에 대하여 점 수를 매겼다. 이 과정에서 검사자 간에 비디오 클립에 대하여 서로 의 견을 나누지 못하게 하고 독립적으로 점수를 부여하도록 하였다.

공인타당도 조사는 임상경력이 가장 많은 아동물리치료사 A (7년 5 개월)의 한글화된 아동용몸통조절척도 점수와 한국판대동작기능 평가 점수를 사용하였다. 공인타당도는 뇌성마비아동의 몸통조절능 력을 가장 잘 측정하는 것으로 공인된 평가도구와 한글화된 아동용 몸통조절척도의 상관성을 조사하는 것이지만, 현재까지는 이에 대 한 공인된 평가도구가 없으므로 뇌성마비아동의 운동발달의 국제적 으로 공인된 평가도구인 한국판대동작기능평가를 사용하였다.

\section{3. 자료분석}

연구대상자의 일반적 특성은 기술통계량을 이용하여 분석하였다. 한글화된 아동용몸통조절척도의 검사자 간 및 검사-재검사 신뢰도 조사를 위하여 급내상관계수(intraclass correlation coefficient, $\mathrm{ICC}_{3,1}$ ) 를 구하였다. $23-28$ ' $\mathrm{ICC} \geq 0.90$,' 'ICC = 0.75-0.90', 'ICC = 0.50-0.75, ' ICC= $\leq 0.50$ ’ 등은 각기 신뢰도가 ‘높음, '양호함, '보통, '좋지 않음을 나타낸 다. 공인타당도를 확인하기 위하여 한글화된 아동용몸통조절척도 와 K-GMFM 간의 상관성에 대하여 스피어만상관계수(Spearman's correlation coefficient) ' $\mathrm{r}$ ' 값을 구하였다. $\mathrm{r}=0.00-0.25$, ' $\mathrm{r}=0.25-0.50$, 'r=0.50-0.75, 'r $\mathrm{r}=0.75<$ ' 등으로 분류하며 각기 '상관관계 없음, '약간 의 상관관계", '중간에서 좋은 상관관계, '높은 상관관계'를 나타내는 것으로 해석한다.29 자료의 통계처리는 window SPSS ver 22.0 (IBM Inc., Armonk, NY, USA)를 사용하였고, 모든 통계학적 유의수준 $\alpha=0.05$ 로 설정하였다.

\section{결 과}

연구대상자의 일반적 특성은 Table 1 그리고 4 명의 검사자가 2 회에 걸 
Table 2. The 1st and 2 nd test scores of the $\mathrm{K}-\mathrm{TCMS}(\mathrm{N}=23)$

\begin{tabular}{|c|c|c|c|c|c|c|c|c|c|c|c|c|}
\hline & \multicolumn{12}{|c|}{ 1st test scores of the K-TCMS } \\
\hline & \multicolumn{3}{|c|}{ Rater A } & \multicolumn{3}{|c|}{ Rater B } & \multicolumn{3}{|c|}{ Rater C } & \multicolumn{3}{|c|}{ Rater D } \\
\hline & M1 (SD) & M2 & Range & M1 (SD) & M2 & Range & M1 (SD) & $\mathrm{M} 2$ & Range & M1 (SD) & M2 & Range \\
\hline SSB & $12.26(4.76)$ & 13 & $0-16$ & $12.48(4.83)$ & 13 & $0-17$ & $12.74(4.60)$ & 14 & $0-17$ & $12.74(5.06)$ & 12 & $0-17$ \\
\hline DSB & $5.39(4.90)$ & 5 & $0-17$ & $6.87(6.00)$ & 6 & $0-20$ & $7.87(6.88)$ & 6 & $0-26$ & $7.26(6.15)$ & 6 & $0-21$ \\
\hline DR & $4.48(2.81)$ & 5 & $0-10$ & $4.57(2.69)$ & 5 & $0-10$ & $4.57(2.61)$ & 5 & $0-10$ & $4.61(2.82)$ & 5 & $0-10$ \\
\hline \multirow[t]{4}{*}{ Total } & $22.13(11.21)$ & 23 & $0-42$ & $23.65(9.69)$ & 22 & $0-41$ & $25.22(12.88)$ & 23 & $0-53$ & $24.61(12.90)$ & 25 & $0-47$ \\
\hline & \multicolumn{12}{|c|}{ 2nd test scores of the K-TCMS } \\
\hline & \multicolumn{3}{|c|}{ Rater A } & \multicolumn{3}{|c|}{ Rater B } & \multicolumn{3}{|c|}{ Rater C } & \multicolumn{3}{|c|}{ Rater D } \\
\hline & M1 (SD) & M2 & Range & M1 (SD) & M2 & Range & M1 (SD) & $\mathrm{M} 2$ & Range & M1 (SD) & $\mathrm{M} 2$ & Range \\
\hline SSB & $12.65(4.71)$ & 14 & $3-20$ & $13.04(5.11)$ & 15 & $3-20$ & $13.04(4.88)$ & 15 & $3-20$ & $13(5.12)$ & 15 & $3-20$ \\
\hline DSB & $6.65(5.72)$ & 6 & $0-17$ & $7.30(6.81)$ & 5 & $0-22$ & $7.61(6.67)$ & 6 & $0-20$ & $7.43(6.91)$ & 5 & $0-21$ \\
\hline DR & $4.43(3.05)$ & 4 & $0-10$ & $4.39(2.87)$ & 5 & $0-10$ & $4.61(2.94)$ & 5 & $0-10$ & $4.57(3.17)$ & 5 & $0-10$ \\
\hline Total & $23.74(12.39)$ & 25 & $3-43$ & $24.74(10.75)$ & 23 & $3-48$ & $25.26(13.48)$ & 24 & $3-48$ & $25.00(14.13)$ & 25 & $3-51$ \\
\hline
\end{tabular}

M1: mean, SD: standard deviation, M2: median, K-TCMS: Korean version of trunk control measurement scale, SSB: static sitting balance, DSB: dynamic sitting balance, DR: dynamic reaching.

Table 3. Inter-rater reliability for the K-TCMS assessed by 4 raters $(N=23)$

\begin{tabular}{lcccccc}
\hline & \multicolumn{2}{c}{ 1st Inter-rater reliability test } & & \multicolumn{2}{c}{ 2nd Inter-rater reliability test } \\
\cline { 2 - 3 } \cline { 6 - 7 } & $\mathrm{ICC}_{3,1}$ & $95 \% \mathrm{Cl}$ & & $\mathrm{ICC}_{3,1}$ & $95 \% \mathrm{Cl}$ \\
\hline SSB & 0.989 & $0.978-0.995$ & & 0.992 & $0.986-0.996$ \\
DSB & 0.980 & $0.962-0.990$ & & 0.981 & $0.964-0.991$ \\
DR & 0.984 & $0.970-0.993$ & & 0.968 & $0.939-0.985$ \\
Total & 0.979 & $0.961-0.990$ & & 0.990 & & $0.980-0.995$ \\
\hline
\end{tabular}

K-TCMS: Korean version of trunk control measurement scale, SSB: static sitting balance, DSB: dynamic sitting balance, DR: dynamic reaching, ICC: intraclass correlation coefficient, Cl: confident interval.

쳐 측정한 한국판아동용몸통조절척도의 중위수, 범위, 평균 그리고 표준편차는 Table 2와같다.

\section{1. 한국판아동용몸통조절척도의 검사자 간 신뢰도}

검사자 $\mathrm{A}, \mathrm{B}, \mathrm{C}, \mathrm{D}$ 가 2 주 간격으로 2 회에 걸쳐 실시한 $\mathrm{K}-\mathrm{TCMS}$ 의 첫 번 째 측정한 점수에 대한검사자 간 신뢰도는 정적 앉기 균형능력, 동적 앉기 균형능력, 동적 팔 뻗기 그리고 총점에 대하여 각기 $\mathrm{ICC}_{3,1}=$ $0.989,0.980,0.984,0.979$ 였고, 두 번째 측정한 점수에 대한 검사자 간 신뢰도는 순서대로 $\mathrm{ICC}_{3,1}=0.992,0.981,0.968$ 그리고 0.990 등 높은 신 뢰도를 나타냈다(Table 3).

\section{2. 한국판아동용몸통조절척도의 검사-재검사 신뢰도}

4 명의 검사자 $(\mathrm{A}, \mathrm{B}, \mathrm{C}, \mathrm{D})$ 별로 정적 앉기 균형능력, 동적 앉기 균형능 력, 동적 팔 뻗기 그리고 총점의 검사-재검사신뢰도는 검사자 $\mathrm{A}$ 는 $\mathrm{ICC}_{3,1}=0.882,0.942,0.938,0.952$ 였고, 검사자 $\mathrm{B}$ 는 $\mathrm{ICC}_{3,1}=0.923,0.827$, $0.908,0.940$, 검사자 $\mathrm{C}$ 는 $\mathrm{ICC}_{3,1}=0.919,0.953,0.894,0.970$ 그리고 검사자 $\mathrm{D}$ 는 $\mathrm{ICC}_{3,1}=0.908,0.947,0.902,0.962$ 로 나타났다(Table 4).

\section{3. 한국판아동용몸통조절척도의 공인타당도}

한국판아동용몸통조절척도의 정적 앉기 균형능력, 동적 앉기 균형 능력, 동적 팔 뻗기, 총점 등과 한국판대동작기능평가의 5 개 영역(눕 기 및 뒤집기, 앉기, 네발기기 및 무릎서기, 서기, 걷기, 뛰기, 깡충뛰기) 점수와 총점과의 상관관계는 정적 앉기 균형능력과 앉기, 네발기기 와 무릎서기, 서기영역 간에 각기 $\mathrm{r}=0.663,0.637,0.667,0.600$ 으로 중간 에서 좋은 상관관계를 나타내었다 $(\mathrm{p}<0.05)$ (Table 5). 또한 동적 팔 뻗 기와 앉기, 네발기기와 무릎서기, 서기, 걷기/달리기/점프하기 영역과 $\mathrm{r}=0.612,0.639,0.634,0.534$ 의 상관관계를 보였다 $(\mathrm{p}<0.05)$ (Table 5).

\section{고 찰}

본 연구는 뇌성마비아동의 정적 앉기 균형능력, 동적 앉기 균형능력, 동적 팔 뻗기에서 몸통조절과 균형능력을 평가하는 아동용몸통조 절척도를 한글화한 후 신뢰도와 공인타당도를 조사하여 한국판아 동용몸통조절척도(K-TCMS)로 표준화하고자 하였다.

모국어가 아닌 외래어로 된 평가도구의 한글화 및 표준화 작업을 위하여 첫째, 해당 분야 전문가 2 인에 의한 한글번역, 2 명이 수행한 한 글번역에 대한 합의, 합의된 한글번역본의 영문 재번역, 원저자와 영 문 재번역본을 이용한 논의 및 합의 그리고 한글매뉴얼 완성 등의 과 정을 거친다. TCMS의 한글화 작업에서 용어, 필요한 도구, 맥락의 이 해를 위하여 원저자와 영문 재 번역본을 이용한 논의와 합의의 과정 은 가장 중요한 단계이다. 둘째, TCMS를 한글화한 것으로 한국판평 가도구가 개발되는 것이 아니므로, 실제로 임상환자를 대상으로 신 뢰도와타당도를 조사해야한다. ${ }^{29}$

신뢰도는 평가도구가 측정하고자 하는 것을 얼마나 정확하게 오 
Table 4. Test-retest reliability for the K-TCMS assessed by 4 raters $(N=23)$

\begin{tabular}{|c|c|c|c|c|c|c|c|c|}
\hline & \multicolumn{2}{|c|}{ Rater A } & \multicolumn{2}{|c|}{ Rater B } & \multicolumn{2}{|c|}{ Rater C } & \multicolumn{2}{|c|}{ Rater D } \\
\hline & $\mathrm{ICC}_{3,1}$ & $95 \% \mathrm{Cl}$ & $\mathrm{ICC}_{3,1}$ & $95 \% \mathrm{Cl}$ & $\mathrm{ICC}_{3,1}$ & $95 \% \mathrm{Cl}$ & $\mathrm{ICC}_{3,1}$ & $95 \% \mathrm{Cl}$ \\
\hline SSB & 0.882 & $0.721-0.950$ & 0.923 & $0.818-0.967$ & 0.919 & $0.810-0.966$ & 0.908 & $0.784-0.961$ \\
\hline DSB & 0.942 & $0.863-0.975$ & 0.827 & $0.591-0.926$ & 0.953 & $0.890-0.980$ & 0.947 & $0.876-0.978$ \\
\hline DR & 0.938 & $0.855-0.974$ & 0.908 & $0.784-0.961$ & 0.894 & $0.750-0.955$ & 0.902 & $0.768-0.958$ \\
\hline Total & 0.952 & $0.887-0.980$ & 0.940 & $0.858-0.974$ & 0.970 & $0.929-0.987$ & 0.962 & $0.911-0.984$ \\
\hline
\end{tabular}

K-TCMS: Korean version of trunk control measurement scale, SSB: static sitting balance, DSB: dynamic sitting balance, DR: dynamic reaching, ICC: intraclass correlation coefficient, Cl: confident interval.

Table 5. Concurrent validity between K-TCMS and K-GMFM ( $\mathrm{N}=23)$

\begin{tabular}{lcccc}
\hline K-GMFM K-TCMS & SSB & DSB & DR & Total score \\
\hline Lying \& rolling & $0.663^{*}$ & $0.461^{*}$ & $0.572^{*}$ & $0.622^{*}$ \\
Sitting & $0.637^{*}$ & $0.446^{*}$ & $0.602^{*}$ & $0.612^{*}$ \\
Crawling \& kneeling & $0.667^{*}$ & $0.467^{*}$ & $0.623^{*}$ & $0.639^{*}$ \\
Standing & $0.600^{*}$ & $0.496^{*}$ & $0.663^{*}$ & $0.634^{*}$ \\
Walking, running, jump & $0.405^{*}$ & $0.478^{*}$ & $0.624^{*}$ & $0.534^{*}$ \\
Total score & $0.599^{*}$ & $0.506^{*}$ & $0.671^{*}$ & $0.639^{*}$
\end{tabular}

K-TCMS: Korean version of trunk control measurement scale, SSB: static sitting balance, DSB: dynamic sitting balance, DR: dynamic reaching, K-GMFM: Korean version of gross motor function measure. ${ }^{*} p<0.05$.

차 없이 측정하는지에 대한 평가의 일관성을 뜻하며 검사자 간신뢰 도와 검사-재검사신뢰도가 대표적이다. 본 연구에서 사용한 ICC 신 뢰도 계수(값)은 0-1의 범위를 가지며 값이 '1'일 경우 검사자 간에 그 리고 반복 검사에서 측정값이 완전히 일치한다는 뜻이다.

검사자 간신뢰도는 2 명 이상의 검사자가 해당 측정도구로 동일한 대상을 측정할 때 검사자들 간의 측정결과가 어느 정도 일치하느냐 를 말한다. 한글화한 TCMS의 정적 앉기 균형능력, 동적 앉기 균형능 력, 그리고 동적 팔 뻗기 등의 3 개 하위척도의 검사자 간 신뢰도는 급 내상관계수 ICC는 0.9 이상의 높은 신뢰도를 나타냈다. 이 결과는 Heyrman 등 ${ }^{14}$ 이 TCMS 개발 당시에 뇌성마비아동(평균연령 11세 3 개 월, GMFCS 제 1 단계 $=11$ 명, 제 2 단계 $=5$ 명, 제 3 단계 $=10$ 명) 26 명을 대상 으로 2 명의 TCMS 검사의 교육과 훈련을 받은 검사자 간 신뢰도 ICC $=0.94-0.98$ 과 유사하였다.

검사-재검사신뢰도는 1 명의 검사자가 한 평가도구를 반복측정 했 을 때 일관된 검사결과가 나오는 정도를 말한다. 반복측정은 피검사 자의 기능적 수준에 변화가 일어나지 않는 시간상의 차이를 두고 수 행해야 한다. 본 연구에서 검사-재검사 신뢰도의 경우, 검사자 $\mathrm{A}, \mathrm{B}, \mathrm{C}$, $\mathrm{D} 4$ 명에서 $\mathrm{ICC}_{3,1}=0.827-0.970$ 의 범위로 '양호함'에서 '높음 수준으로 Heyrman 등 ${ }^{14}$ 의 ICC $=0.91-0.97$ 에 비해 약간 낮은 수준이다. 이 같은 차이가 난 것은 검사-재검사에 참여한 치료사의 TCMS에 대한 경험 의 차이에 의한 것으로 생각된다. 원 저자의 연구에서 검사-재검사 신 뢰도에 참여한 검사자는 TCMS의 교육을 담당한 TCMS에 대한 이론 과 실기가 풍부한 치료사였다. 본 연구에서도 임상경력이 가장 많고
교육을 담당했던 검사자 $\mathrm{D}$ 의 경우 뇌성마비아동의 평가경험이 가장 많은 치료사로 $\mathrm{ICC}_{3,1}=0.902-0.962$ 로 원저자의 검사-재검사 신뢰도 값과 유사하였다.

공인타당도는 측정할 내용을 이미 공인된 검사도구(gold standard) 와 비교하는 것이다. 한국판몸통손상조절척도의 공인타당도를 검사 하기 위하여 한국판대동작기능평가를 선택하였다. K-GMFM 에서 평 가하는 뒤집기, 앉기, 서기, 걷기, 깡충 뛰기 등은 기본적으로 몸통조절 이 요구된다. 본 연구에서는 K-GMFM-88을 사용하였다. ${ }^{30} \mathrm{GMFM}-66$ 은 총점만 구할 수 있어 영역별 점수를 갖지 못하기 때문이다. 본 연구 의 결과에서는 K-GMFM의 총점과 K-TCMS의 총점, 3 개의 하위척도 와 모두 중간에서 좋은 수준의 '양'의 상관관계를 가져 K-TCMS의 공 인타당도를 지지하는 것으로 볼 수 있다. K-GMFM의 5 개 영역점수도 K-TCMS의 총점 및 다른 하위척도들과 유의한 상관관계를 가졌다.

특히, GMFM의 모든 영역에서 TCMS의 dynamic sitting balance가 dynamic reaching보다 상관관계가 더 낮게 나타났다. GMFM의 항목 들은 몸통을 한 자세로 유지하기보다는 한 자세에서 다른 자세로 이 행하는 동작들이 많고, TCMS의 동적 앉기 균형능력은 앉은 자세에 서 상부 체간과 하부 체간의 회전동작, 양쪽 골반의 분리 등을 검사 하는 항목으로 실제로 보다 역동적인 항목들로 구성되는 동적 팔 뻗 기와 상관관계가 높게 나타난 것으로 생각된다.

GMFM의 앉기 영역과의 상관관계가 동적 앉기 균형능력과 상관 관계가 낮은 것은 TCMS는 몸통조절이라는 움직임에서 매우 중요한 질적인 요소를 강조하고 $\mathrm{GMFM}$ 은 양적인 발달을 측정하는 속성을 가지고 있기 때문으로 뇌성마비아동의 운동기능을 측정할 때는 두 가지 평가도구를 상호보완적으로 함께 사용하는 것이 좋을 것이다.

본 연구의 제한점으로는 뇌성마비아동의 수가 적었다는 것이며 그 중에서도 10 대 아동의 수가 많지 않아 전체 뇌성마비아동에게 연 구결과를 일반화하기 어렵다는 것이다. 또한 단일 기관에서 종사하 는 치료사들을 대상으로만 신뢰도를 구하였으므로 추후 다 기관의 임상에서 참여하는 신뢰도 조사가 필요할 것이다. 앞으로 K-TCMS를 사용하는 기관과 치료사들은 K-TCMS를 환자에게 실제로 적용하기 전에 한글매뉴얼을 충분히 숙지하고 최소한 2 명의 뇌성마비아동을 대상으로 기관의 아동물리치료사들의 신뢰도를 확인한 후 사용해 
야 할 것이다. 또한 K-TCMS가 다양한 물리치료 중재의 효과를 입증 할 수 있는 평가도구인지에 대한 연구도 이루어져야 할 것이다.

본 연구의 결과를 종합해 볼 때, K-TCMS는 신뢰도와 공인타당도 를 갖춘 임상과 연구의 목적으로 뇌성마비 환자의 앉은 자세에서 균 형과 몸통조절력을 평가하고 중재에 적용할 수 있는 유용한 평가도 구라고 생각된다.

\section{참고문헌}

1. Rosenbaum P, Paneth N, Leviton A et al. A report: the definition and classification of cerebral palsy April 2006. Dev Med Child Neurol Suppl. 2007;49(6):480.

2. Brogren E, Hadders-Algra M, Forssberg H. Postural control in sitting children with cerebral palsy. Neuroscience and Biobehavioral Reviews. 1998;22(4):591-6.

3. Donker, SF, Ledebt A, Roerdink M et al. Children with cerebral palsy exhibit greater and more regular postural sway than typically developing children. Experimental Brain Research. 2008;184:363-70.

4. Curtis DJ, Butler P, Saavedra S et al. The central role of trunk control in the gross motor function of children with cerebral palsy: A retrospective cross-sectional study. Dev Med Child Neurol. 2015;57(4):351-7.

5. Carlberg EB, Hadders-Algra M. Postural control in sitting children with cerebral palsy. In: Carlberg EB, Hadders-Algra M, eds, Postural control a key issue in developmental disorders, London, Mac Keith Press. 2008: 74-96.

6. Verheyden G, Mertin J, Preger R et al. The trunk impairment scale: a new tool to measure motor impairment of the trunk after stroke. Clinical Rehabilitation. 2004;18:326-34.

7. Saavedra S, Joshi A, Wollacott MH et al. Eye-hand coordination in children with cerebral palsy. Experimental Brain Research. 2009;192(2): 155-65.

8. Saavedra S, Woollacott M, Donkleaar P. Head stability during quite sitting in children with cerebral palsy: Effect of vision and trunk support. Experimental Brain Research. 2010;201:13-23.

9. Heyrman L, Desloovere K, Molenaers G et al. Clinical characteristics of impaired trunk control in children with spastic cerebral palsy. Research in Developmental Disabilities. 2012;34:327-34.

10. Franki I, De Cat J, Deschepper E et al. A clinical decision framework for the identification of main problems and treatment goals for ambulant children with bilateral spastic cerebral palsy. Res Dev Disabil. 2014; 35(5):1160-76.

11. Fife SE, Roxborough LA, Armstrong RW et al. Development of a clinical measure of postural control for assessment of adaptive seating in children with neuromotor disabilities. Physical Therapy. 1991;71:981-93.

12. Bartlett D, Purdie B. Testing of the spinal alignment and range of motion measure: A discriminative measure of posture and flexibility for children with cerebral palsy. DMCN. 2005;47:739-43.

13. Butler PB, Saavedra S, Sofranac M et al. Refinement, reliability, and va- lidity of the segmental assessment of trunk control. Pediatric Physical Therapy. 2010;22:246-57.

14. Heyrman L, Molenaers G, Desloovere K et al. A clinical tool to mesure trunk control in children with cerebral palsy: The trunk control measurement scale. Research in Developmental Disabilities. 2011;32:262435 .

15. Bañas BB, Gorgon EJ. Clinimetric properties of sitting balance measures for children with cerebral palsy: A systematic review. Phys Occup Ther Pediatr. 2014;34(3):313-34.

16. Sæther R, Helbostad JL, Adde L et al. The relationship between trunk control in sitting and during gait in children and adolescents with cerebral palsy. Dev Med Child Neurol. 2015;57:344-50.

17. Heyrman L, Hilde F, Guy M et al. Altered trunk movements during gait in children with spastic diplegia: compensatory or underlying trunk control deficit? Res Dev Disabil. 2014;35:2044-52.

18. Meyns P, Pans L, Plasmans K et al. The effect of additional virtual reality training on balance in children with cerebral palsy after lower limb surgery: a feasibility study. Games Health J. 2017;6(1):1-10.

19. Saether R, Helbostad JL, Riphagen II et al. Clinical tools to assess balance in children and adults with cerebral palsy: a systematic review. Dev Med Child Neurol. 2013;55:988-99.

20. Mastos M, Miller K, Eliasson AC et al. Goal-directed training: linking theories of treatment to clinical practice for improved functional activities in daily life. Clin Rehabil. 2007;21:47-55.

21. Palisano RJ, Rosenbaum PL, Walters SD et al. Development and reliability of a system to classify gross motor function in children with cerebral palsy. Dev Med Child Neurol. 1997;39:214-23.

22. Ko J, Woo JH, Her JG. The reliability and concurrent validity of the GMFCS for children with cerebral palsy. J Phys Ther Sci. 2011;23(2):255-8.

23. Jeong DH. Reliability and validity of the CAP for computer access assessment of persons with physical disabilities. J Korean Soc Phys Ther. 2015;27:30-7.

24. Kim DY, Choi JD, Ki KI. A reliability study of sit-to-walk for dynamic balance assessment in stroke patient. J Korean Soc Phys Ther. 2013; 25(5):303-10.

25. Chang WN, Lee KB, Yeom JW et al. Analysis of intrarater and interrater reliability of trunk repositioning error test using a portable digital inclinometer. J Korean Soc Phys Ther. 2013;25(4):210-6.

26. Lee IH. Reliability of visual gait analysis according to clinical experience level of physical therapists. J Korean Soc Phys Ther. 2013;25(4):174-9.

27. Yoo SH, Ha HK, Lee HJ. Korean cultural adaptation of working alliance inventory and its reliability. Korean Soc Phys Ther. 2014;26(2):90-6.

28. Ko JY, You YG. Reliability and responsiveness of the Korean version of the trunk impairment scale for stroke patients. J Korean Soc Phys Ther. 2015;27(4):175-82.

29. Kim HS, Her JG, Ko JY et al. Reliability, concurrent validity, and responsiveness of the fugl-meyer assessment (FMA) for hemiplegic patients. J. Phys. Ther. Sci. 2012;24(9):893-9.

30. Ko J, Kim M. Reliability and responsiveness of the gross motor function measure-88 in children with cerebral palsy. Phys Ther. 2013;93(3):393400. 